\title{
The Meanings of "Imagine" Part I: Constructive Imagination
}

(In Philosophy Compass 8(3): 220-230, 2013. Please cite published version!)

Imagine this " $\mathrm{g}$ " - on the page or screen before you-is a dragon in disguise. Slowly it rears up, standing on its lower loop and sprouting wings from its upper loop. Purple eyes open on its black face, which emerges from the upper-right nub of the " $g$ ", and look at you curiously, as it decides whether to open its mouth and scorch you or fly away and be gone forever. It flies away and leaves you un-burnt, but alone.

The philosophy and cognitive science of imagination addresses at least three related questions about the sort of imaginative representations you just had.

1) How do they arise?

2) What are their typical characteristics viewed synchronically, including ones that distinguish them from related states, like belief or perception?

3) What are their downstream consequences on emotion and action, especially pretense (or make-believe)?

These are related, because the answers to 1 and 3 will inform the answer to 2; in other words, the etiology and forward effects of imaginative representations are central to their nature. So my overall aim is to canvas some major theoretical and empirical approaches to these questions. In the present article (Part I), after clarifying the language of "imagining," I address 1, showing how constructive imagination constantly incorporates elements of reality-oriented cognition, like beliefs and perceptions. In the next article ( $\underline{\text { Part II }), ~ I ' l l ~ a d d r e s s ~} 2$ and 3.

Before we get to the cognitive science, let's ask a linguistic question: what do we mean by "imagine," "imagining," and "imagination"?

Each of these words has different, though related, uses. And failure to distinguish them can hinder the clarity of discussion in both philosophy and psychology. So let's do some conceptual analysis, before addressing questions 1-3.1

Return to your dragon imagining. There are three distinct claims one might express with

"X imagines a purple-eyed dragon."

Or:

"X is imagining a purple-eyed dragon."

\footnotetext{
${ }^{1}$ White (1990) extensively discusses the semantic value of "imagination" and cognates. His approach is very different from mine, so I encourage the reader to compare the two approaches.
} 
First, the sentences in question (more the second) can express that $\mathrm{X}$ is engaged in a temporally-extended constructive process of assembling mental representations of a dragon with purple eyes. I'll call this constructive imagining.

Second, one might be saying that $\mathrm{X}$ has a cognitive attitude besides belief to the content there is a dragon before me. I'll call this attitude imagining (alternately, fictional imagining will also take this attitudinal sense).

Third, the words "imagine" or "imagining" can indicate an imagistic representational format for what's happening in one's mind. I'll call this imagistic imagining.

I'll explain these in turn.

Constructive imagining. Sometimes it's hard work to come up with ideas. You might try out different features of an imagined scene to see which ones work. Or it might take time to come up with the initial representation-the premise-itself. Or once you've imagined a dragon, it may take effort to hold it there, which is also a process. You might say, "It took me a while to imagine the dragon coming out of the ' $\mathrm{g}$ '." In saying that, you would not be saying it took you time to have a certain attitude toward the contents. You regarded what you were doing as fictional from the start. Rather, it took you time to generate the representations with those contents in the first place-an imaginative process.

Attitude imagining. Humans have the flexibility to take different attitudes toward a given content $c$. We can believe that $c$, fear that $c$, hope that $c$, assume that $c$ for the sake of argument, and so on. Cognitive attitudes, like belief, contrast with conative attitudes, like desires. As Nishi Shah and David Velleman (2005: 497, their italics) put it, "Propositional attitudes can be divided into the cognitive attitudes, which treat their propositional objects as satisfied or true, and the conative attitudes, which treat their propositional objects as to be satisfied or to be made true." In other words, a cognitive attitude encodes what the world or some portion of it is or might be like, whereas a conative attitude represents what you would like it to be like. So one thing we could be saying with "X imagines that $c$ " is that X takes a cognitive attitude toward $c$ that nevertheless treats $c$ as somehow fictional, as presumably you did with the contents of your dragon representation. (To have a noun phrase that parallels "a belief," we also often use "an imagining." For example, "your dragon representation was not a belief, but an imagining.")

Now here's a key point. Not every mental state that comes from constructive imagining is attitude imagining in the sense of being regarded as fiction. A detective, for example, may engage in a constructive imaginative process to figure out how a crime was committed, where known pieces of evidence constrain her imagining. But she may still believe the output of this constructive imagining, say, the content that the murder was committed with the garden tool. In this case, we would say that the detective "imagined" how the crime took place, though we would not thereby imply that she took the events so imagined to be fiction. So constructive imagining doesn't entail attitude imagining. ${ }^{2}$

\footnotetext{
${ }^{2}$ Exercise for the reader: does the entailment go the other way?
} 
Imagistic imagining. One's mental representations can be structured in different ways, and some representations seem ${ }^{3}$ to be "imagistic." You can visualize a cat when none is there and auditorily imagine a voice in a silent room. Such experiences are typically called "mental imagery," but unsurprisingly, "imagining" is used as well. Imagistic representations can be thought of as re-creations of perceptual experiences, to use a term from Gregory Currie and Ian Ravenscroft (2002); one visualizes, engages in tactile or auditory imagining, or even imagines smells and flavors. When I recall the color of my neighbor's dog on the street where I grew up, I'm "imagining" in this sense. ${ }^{4}$

Importantly, imagistic imagining also doesn't entail attitude imagining. I perfectly well believe that the dog Matt was the color I "imagine," so my imagistic imagining didn't have a fictional attitude valence. David Kaplan (1968: 208) implies this point when he writes:

\footnotetext{
Many of our beliefs have the form: 'The color of her hair is __', or 'The song he was singing went_', where the blanks are filled with images, sensory impressions, or what have you, but certainly not words. If we cannot even say it with words but have to paint it or sing it, we certainly cannot believe it with words.
}

The point is that imagery is involved in many beliefs, possibly as a constituent of a larger structure, which the agent takes to represent reality as opposed to fiction. This often happens with vivid memories: imagistic imagining without attitude imagining (see also Kind 2001 for this point).

Conversely, attitude imaginings needn't have an imagistic representational format. When I imagine, on reading Lord of the Rings, that elves can live forever, I'm fictionally imagining a proposition that I couldn't imagine using mental imagery. It would take too long! So presumably I represent this in a more abstract symbolic code, such as Fodor's (1975) language of thought.

So "imagine" and "imagining" take different senses; either can designate (i) a constructive process, (ii) an attitude, or (iii) mental imagery. This is not massive ambiguity, however, because the different phenomena designated often go together: constructive imagining can generate imagery regarded as fictional. In fact, all three senses apply to your dragon "imagining": you generated the dragon representations by a constructive process; your attitude to the dragon was as of fiction; and your representations were probably imagistic - at least visual. But it would be tedious to say, "I imagine, imagine, and imagine," so we often just say "I imagine." Thus, as a matter of pragmatics, more than one sense of "imagine" can be selected by context.

\footnotetext{
3 See Kosslyn, Thompson, and Ganis (2006) for an overview.

4 My distinction between attitude imagining and imagistic imagining somewhat resembles Goldman's (2006) distinction between S-imagination and E-imagination, where the former is propositional (think supposition) and the latter is imagistic (think enactive). But it's not the same distinction. On my analysis, attitude imaginings can have various representational formats, an imagistic format being one of them. The distinction between belief and the attitude of fictive imagining is thus orthogonal to the distinction between propositional and imagistic representational formats.
} 
Nevertheless, we philosophers must realize that, as a matter of meaning, none of the three senses entails the others. ${ }^{5}$

Now what about "imagination"? Typical sentences are:

(a) "He has a good imagination."

(b) "There was a failure of imagination."

(c) "She has a dirty imagination."

(d) "In my imagination, elves are immortal."

(e) "That's just your imagination."

(f) "Her face is vivid in my imagination."

(g) "I could see it in my imagination."

The different uses of "imagination" in these sentences correspond to the different uses of "imagine" and "imagining" just discussed.

Thus, "imagination" often refers to a capacity to form novel representations. This use corresponds to constructive imagining. Thinking of a motorcycle doesn't take much imagination (in this sense) if you've seen a motorcycle. But the first person to have this idea had a tremendous constructive imagination, or "a good imagination" (a). Conversely, one who fails to generate ideas she ought to has a "failure of imagination" (b). (c) also uses "imagination" in the constructive sense and describes someone with a strong capacity for inventing perversities.

The attitude sense of "imagination" refers to the collection of one's mental representations one takes as fictional. (d), for example, claims that the speaker's fictional imaginings represent that elves are immortal. Sometimes, though not always, "in X's imagination" has this attitude sense. Again, not all the products of constructive imagination will be mere imaginings in the attitude sense. The detective used her constructive imagination to figure out how the crime was committed, but the end result was belief, not fictional imagining. Furthermore, (e) suggests that the constructive sense of "imagination" is distinct from the attitudinal sense. (e) implies that the addressee has a false belief, which the speaker thinks the addressee's constructive imagination unwittingly generated, with no contribution from reality.

To see "imagination" used in the constructive sense in psychology, consider a passage from Paul Harris. In the Introduction to The Work of the Imagination, Harris (2000: ix-x) writes about the explosion of human culture that archeology reveals in the Upper Paleolithic about 40,000 years ago:

... alongside this shift in the organisation of food and shelter, another set of activities emerged that can be less easily linked to the pragmatics of survival: cave painting, the diversification and stylisation of tools, the manufacture of bodily ornaments and burial practices....

In a nutshell, the material record testifies to a new power of the imagination. Some of the newly emerging artefacts have much the same function as props in children's games of make-believe.

${ }^{5}$ Relatedly, Kind (forthcoming) argues that "imagination" cannot refer to just one thing and still do the various explanatory work philosophers have asked it to do. 
The last sentence refers to Kendall Walton's (1990) theory of artistic representation, which holds that art functions like props in games of make-believe: what is represented in an art work is what we are prescribed to imagine (attitude sense) by the game in which the artwork is a prop. So that idea does connect constructive imagination to the generation of fiction. But Harris clearly does not think that fictions are the only products of imagination; he says "Some of the newly emerging artefacts ..." (my italics). So someone wishing to understand imaginative capacities should focus both on the creation of fictions and on reality-oriented tools. The process by which an adult hunter re-imagines a branch as a bow for hunting must have much in common with the process by which a child re-imagines a branch as a toy bow. Discussions of "imagination" that focus solely on the generation of fiction and pretense can easily obscure this commonality.

I think we should take the constructive sense of "imagination" to refer to a capacity and not a faculty, since "faculty" seems to imply a unified, autonomous, specialized mental system-a "module," so to speak. ${ }^{6}$ But novel ideas have diverse internal sources. Perceptions, beliefs, emotions, mis-perceptions, rational inference systems, irrational biases, items in memory, etc. are all partial sources of novel ideas, so they are all potentially components of constructive imagination. Otherwise put, human imagination is built out of components, many of which also serve other purposes; it's not a single "faculty." The great ancient anatomist Galen discovered multiple biological purposes for every bone he analyzed; I think something similar holds for the building blocks of imagination: abilities such as memory and perception serve both reality tracking and constructive imagination (more on this below). ${ }^{7}$ Imagination, in part, is the capacity to use them for more than one purpose.

Finally, "imagination" can refer to one's set of occurrent mental images-a kind of imagistic workspace. Often, "in my imagination" takes this sense, as in (f) and (g). (f) expresses that the speaker has a mental image of a face. So as before, not everything "in the imagination" in this sense is fiction, or attitude imagining. The dragon was. But much imagery "in the imagination" is just recollected veridical perception, like the memory of a face.

Let's summarize these points in a chart:

${ }^{6}$ Jerry Fodor (1983) explicitly mentions faculty psychology as a precursor to his modularity. 7 This view also fits well with what we know of natural selection; natural selection builds new features out of components already in existence. 


\begin{tabular}{|l|l|l|}
\hline & $\begin{array}{l}\text { "X imagines/ is } \\
\text { imagining } c^{\prime}\end{array}$ & "Imagination" \\
\hline constructive sense & $\begin{array}{l}\text { Expresses that X is } \\
\text { engaged in a process of } \\
\text { coming up with mental } \\
\text { representations that have } \\
c \text { content }\end{array}$ & $\begin{array}{l}\text { Refers to the capacity to } \\
\text { form novel } \\
\text { representations }\end{array}$ \\
\hline attitude sense & $\begin{array}{l}\text { Expresses that X's } \\
\text { cognitive system } \\
\text { represents } c \text {, though } \\
\text { taking it to be non-real }\end{array}$ & $\begin{array}{l}\text { Refers to one's collection } \\
\text { of fictional attitude } \\
\text { imaginings }\end{array}$ \\
\hline imagistic sense & $\begin{array}{l}\text { represses that X's mental } \\
\text { imagistic or mental } \\
\text { imagery, i.e., formatted } \\
\text { like perception }\end{array}$ & $\begin{array}{l}\text { Refers to one's occurrent } \\
\text { collection of imagistic } \\
\text { imaginings }\end{array}$ \\
\hline
\end{tabular}

Understanding these distinctions is important, first, for avoiding fallacious inferences; second, for critically understanding central philosophical theses; and third, for posing philosophical questions more precisely. ${ }^{8}$ Whenever encountering a philosophical thesis about "imagination," one should ask: what is being claimed?

Now with these distinctions in hand, let's turn to the questions raised at the outset. We'll start with constructive imagination (1). Part II will address 2 and 3.

\title{
Constructive Imagination: generating new representations
}

David Hume (1748/1993: 31) famously writes:

\begin{abstract}
Nothing is more free than the imagination of man; and though it cannot exceed that original stock of ideas furnished by the internal and external senses, it has unlimited power of mixing, compounding, separating, and dividing these ideas, in all the varieties of fiction and vision.
\end{abstract}

Hume is talking about constructive imagination. His use of the word "free" here expresses the feeling of mystery that attends the question of how new ideas arise. There are several sources of the mystery, but one is that we only consciously experience the products of constructive imagination, remaining largely in the dark as to how they got there.

Yet the seeds of a theory are already to be found in the Hume quotation. Furthermore, contemporary cognitive science lends credibility to his view. Let's take Hume as holding:

\footnotetext{
${ }^{8}$ Many philosophical questions deploy "imagine" or "imagination," without being clear which sense is meant. For example: if I can imagine that $p$, does that entail it is possible that $p$ ? For an exploration of this issue, see Kung (2010).
} 
Sensory Construction Thesis: constructive imagination includes the capacity to combine elements of ideas from memory that were acquired by perceptual and other experience, such as emotion.

Hume holds this view partly to defend empiricism. For it seems problematic for empiricism that we can have ideas of things we've never witnessed, like the Minotaur. But the Minotaur idea, Hume points out, is composed of elements we have seen: the body of a man and the head of a bull. So it's not a counterexample to empiricism as easily as we might think. The freedom Hume refers to, then, is freedom to combine what's already in perceptual memory in novel ways. Interestingly, this old view of imagination, regardless of whether it convincingly supports empiricism, coheres with findings in contemporary cognitive neuroscience.

In general, the sensory cortices of the brain are active when one imagines contents in a sensory modality. Visualizing and seeing, for example, both activate the visual cortices. Furthermore, the sensory cortices seem to be implicated in the combining of elements from disparate experiences. An experiment from Slotnick, Thompson, and Kosslyn (2005) is illustrative. While in an fMRI scanner, subjects were visually presented with the image of a rotating checkerboard pattern, shaped like a bowtie. In another condition, subjects were presented with just the outside edges of the bowtie shape, still rotating, while being instructed to visualize the missing bowtie; intermittently, subjects in this condition (and others) were asked to identify whether a red dot that appeared on the screen landed on the area where the bowtie would have been. ${ }^{9}$ Two results emerged that are important for present purposes. First, subjects correctly identified whether the dot would have landed on the moving bowtie. Second, the activation patterns in the early visual cortices were similar for both the perception and imagery conditions. So the overall causal pathway seems to be:

Step 1: the rotating bowtie is processed and represented by the visual cortices. Step 2: information about the geometry and motion of the bowtie is stored in memory.

Step 3: that information is later used to generate imagistic representations of the bowtie in the same visual cortices, even when it's not seen.

Step 4: this visual imagining of the bowtie is used to judge whether the red dot lands where the bowtie would have been.

Thus, subjects combined elements of one (remembered) visual experience with an element of another (present) experience to generate a new idea: a checkered bowtie shape with a red dot on it in a particular place.

The point is simple, and one Hume would have recognized: perception and perceptual memory function as critical building blocks for constructive imagination.

\footnotetext{
${ }^{9}$ There were also two other conditions in the study designed to rule out hypotheses that don't concern us here. See also Kosslyn, Thompson, and Ganis (2006: 110-112) for discussion.
} 
The Sensory Construction Thesis helps us understand the generation of novel mental imagery. But it's far from explaining all that should be explained. To see this, consider how it might explain a visual imagining of a dancing cat. We've seen cats, and we've seen dancing. So the Thesis seems to say we just put the two recollected images together. But there are two problems. First, two people might imagine different things: one visualizes a cat in a tutu dancing ballet, while the other imagines a cat in a black hat jazz dancing. This may be so, even though the two imaginers have both seen both types of dancing. So the Sensory Construction Thesis has an under-specification problem: even for a specific imagining task, it doesn't explain exactly which elements from sensory memory will be selected for combination. Second, the Thesis does not explain how geometric transformation of items from memory occurs. One can't just superimpose an image of dancing on top of a cat image. That would yield a cat behind a dancer, not a dancing cat. This problem doesn't arise with the red dot on the bowtie or the bull's head on the man's body, since in neither case does the imagined geometry of items from memory need transformation. But in imagining a dancing cat, you put the cat's body into positions in which you've never seen a cat. Those positions will be based on dancing you've seen, but that involves people. So the geometry of the actually perceived dancing must be abstracted from the perceptual particulars (human skin, hair, etc.) and applied to the mental image of a cat. And the Sensory Construction Thesis doesn't tell us how this works. Of course, the under-specification and geometric transformation problems don't show the Thesis is wrong, but they do show it's only the start of an explanation of the generation of novel mental imagery. ${ }^{10}$

Let's now turn to a second thesis about constructive imagination, which can be illustrated with a brief phenomenological experiment. Instructions: imagine a female lion in the bushes looking out on a herd of grazing antelope; then imagine she charges them. What do you imagine next?

I'm guessing you imagine the antelope run away. ${ }^{11}$ But why? Imagining this wasn't in the instructions. You could have imagined them staying put, though you didn't. The answer, around which some consensus has emerged, is that one's beliefs inferentially govern transitions from initial imaginings to later imaginings. The proposition a lion charges antelope does not by itself entail the antelope run away. But if we add antelope flee charging lions, which you believe, then we get the entailment.

Imagining (by instruction): a lion charges antelope

Belief (inferential background): antelope flee charging lions Imagining (generated): the antelope run away

The thesis this suggests is:

\footnotetext{
10 Thanks to Alan Richardson (seminar discussion) for the dancing cat example.

11 And this would be so even if you were imagining the herd from a perspective from which you've never seen a herd; thus, the unfolding of the imaginings can't be accounted for by perceptual habituation alone. Thanks to Bence Nanay (personal communication) for raising this issue.
} 
Belief Governance Thesis: constructive imagination uses beliefs by default to infer new imaginings from imaginings that have already occurred.

The significance of "by default" is that many operations of constructive imagination can be voluntarily altered, as Hume suggests, or altered in other ways; nevertheless, imagination does proceed as described by the Belief Governance Thesis unless special circumstances arise. For example, you probably imagined a lion without a mane, because my instructions specified "female lion" and you believe female lions have no manes. Thus, this Thesis identifies a process that is part of the general pattern of beliefs' providing the background that supports inference. (I should emphasize also that this Thesis-and constructive imagination generally-applies to the generation of propositional imaginings, not just imagistic imaginings. For example, my imagining that a fictional character feels hopeful, which may be generated by background beliefs about how people feel in certain circumstances, is in the first instance propositional, not imagistic.)

The Belief Governance Thesis has extensive empirical support.

First, psychologists Deena Weisberg and Joshua Goodstein (2009) provide direct evidence that individuals following a story import elements of what they take to be reality (in other words, their beliefs) into their understanding of what happens in the story. They had subjects read stories and then simply asked them questions about what else would be true "in the story." They found subjects held that mathematical, scientific, conventional (about social norms), and contingent facts were true in the stories, even though these were not given by the text. Interestingly, however, how "near" the story was to reality modulated this effect: subjects reading more outlandish stories, e.g., where people could teleport, were less likely to import contingent facts, though mathematical facts stayed fairly constant. I'll discuss this wrinkle momentarily.

Second, Harris (2000: ch. 2) provides indirect evidence from children's pretending that beliefs-particularly beliefs about causal powers-are not only imported, but also used in generating new imaginings from previous ones. For example, two-year-olds who see 'Naughty Teddy' pouring an empty container with pretend milk onto a certain part of the floor will pretend to dry up the milk from that part of the floor, not others. This suggests that children use causal beliefs about what happens when milk is poured to infer what to imagine next in games of makebelieve.

As mentioned, the view expressed by the Belief Governance Thesis has a fair amount of consensus in philosophy and psychology. Shaun Nichols and Stephen Stich (2000: 123) develop the view in more theoretical detail (their "pretenseinitiating representation" means roughly what I mean by "initial imagining"):

In order to fill out a rich and useful description of what the world would be like if the pretense-initiating representation were true, the system is going to require lots of additional information.... the additional information is going to come from the pretender's Belief Box. So, as a first pass, let us assume that the inference mechanism elaborates a rich description of what the pretend world would be like by 
taking both the pretense-initiating representations and all the representations in the Belief Box as premises.

So roughly all of one's beliefs are potentially implicated in inferential elaboration on initial imaginings. This seems close to right. Nichols and Stich quickly note, however, that this view needs to be qualified: beliefs that contradict the pretense-initiating representations don't get implicated in the inferential elaboration-otherwise there would be "inferential chaos" in what one imagines. This is the key insight. If I imagine, for example, a steamroller running over the fire hydrant outside my window, I use all my relevant background beliefs in generating subsequent imaginings, except my belief that there is no such steamroller. So the view that emerges is that constructive imagination is largely the inferential working-out of what would happen in the world (as one believes it to be), if it were minimally altered in the ways indicated by the pretense-initiating representations. And beliefs that contradict initial imaginings get bracketed (as I like to put it) - excluded from the inferential background of imaginative elaboration.

Now we've made some progress, but the flexibility of constructive imagination is such that the Belief Governance Thesis needs to be further qualified. Most of us are familiar with a variety of fictional genres, including ones whose "rules" differ from those of believed reality. Imagine a nice young boy who is a werewolf; now imagine the full moon rising. What do you imagine next? Now imagine a photon torpedo shooting through space at a space ship; now imagine the ship jumps into hyperdrive a split second before the torpedo hits. What do you imagine next?

As with the lioness and antelope, these are cases of inferential elaborationhence constructive imagining - on initial imaginings. I didn't tell you about the metamorphosis into wolf form or about the torpedo missing the ship; you inferred them. But the Belief Governance Thesis can't explain these transitions, since no one believes either that werewolves metamorphose at full moon or that hyperdrive takes a ship to light speed. Nevertheless, those are exactly the contents that one must represent in some way in order to perform the imaginative inferences you just performed.

So the question arises: by what sort of mental state are the non-believed contents represented that are used to support imaginative inferences? This question is further pressed on us by recalling that, for the outlandish stories in the Weisberg and Goodstein study, subjects were hesitant to import their contingent and conventional beliefs into story cognition. Something besides belief seems to bridge the inferential the gap between initial imaginings and later imaginings in some cases.

One possibility we should consider is that second-order beliefs, or beliefs about what others believe, bridge the gap. Along these lines, Walton (1990: 150161) critically discusses the Mutual Belief Principle, which says (roughly) that our beliefs about what was believed in the society in which a story was constructed help 
us extrapolate what we ought ${ }^{12}$ to imagine in the story world. On this view, if I'm imagining (say) witches in a story and believe that the society in which the story was written believed that witches were blind, then it becomes fictional in the story that the witches are blind. This may in fact be how inferential elaboration works some of the time. But it doesn't work this way always, as Walton is quick to point out. And it doesn't work this way in the present cases, since stories about werewolves needn't be written from within werewolf-believing societies in order to be understood, and you don't need to believe others believe in hyperdrives in order to perform the inferential elaboration about the torpedo. Thus, beliefs about people's beliefs can't support the imaginative inferences under consideration, so the Mutual Belief Principle doesn't do all the additional explanatory work we need.

Here I think it's useful to posit genre truths and genre truth attitudes. Genre truths are contents that are taken as given in the background of a fictional genre. Genre truth attitudes are cognitive attitudes, a species of fictional imagining, dedicated to representing genre truths. So let's consider one more thesis.

Genre Truth Governance Thesis: in the context of specific genres, constructive imagination uses genre truth attitudes (in addition to the relevant beliefs) to infer new imaginings from imaginings that have already occurred.

The view, then, is that certain contextual cues, like mention of magic or spaceships, trigger the use of genre truth attitudes for purposes of inferential elaboration on initial imaginings. This is similar to the finding in developmental psychology that certain cues on the part of adults, like conspicuous smiling and looking, trigger children's understanding of actions as pretending (Lillard and Witherington 2004). The processes posited here are developmentally downstream, but they function in similar fashion. Just as looking and smiling trigger a toddler's understanding of pretense, mention of magic and hyperdrives trigger the use of genre truth attitudes in understanding a story and drawing inferences. This is not to say that all beliefs become otiose; rather, those that contradict the genre truths become bracketed, with the rest of one's beliefs remaining the default inferential background. ${ }^{13}$

Let's take stock. We've considered two facets of constructive imagination. On the one hand, imagination produces novel mental imagery; on the other hand, it produces attitudes of fictional imagining. (Some produced representations, of course, are both imagistic and fictional; some, however, are propositional and

\footnotetext{
12 Notice the "ought." Walton is presenting the Mutual Belief Principle as a (possible) generator of what is fictional (fictionally true) in a given story, where what is fictional is what we in some sense ought to imagine, if we're playing the game one must play in order to comprehend the story. Thus, Walton's focus is a bit different from mine, since I'm considering the actual psychological principles behind imagination. Nevertheless, it should be clear why the Mutual Belief Principle is pertinent here.

13 I think genre truth attitudes may in part be what Nichols and Stich $(2000,2003)$ are getting at with their idea of the "script elaborator." Note also that the Mutual Belief Principle can be subsumed under the Genre Truth Governance Thesis: beliefs about mutual beliefs may yield genre truths, though that's not the only route to genre truths. Thanks to Sam Liao for helpful discussion on these issues.
} 
fictional, while others are imagistic and non-fictional.) The Sensory Construction Thesis is a partial specification of how new mental imagery is generated: we combine elements of representations derived from perception. The Belief Governance and Genre Truth Governance Theses are about how new attitude imaginings are generated from ones already given; inferential elaboration occurs constantly, so inferential backgrounds are needed. Beliefs supply the background in the first instance; genre truth attitudes do so in the second instance (with beliefs about beliefs perhaps playing a role sometimes). Two things about all this should impress us. First, constructive imagining is often not much of a departure from reality at all; rather, it is a selective playing with elements of ideas already accepted as representing reality, like percepts and beliefs. Second, when constructive imagination does depart more daringly from reality, two things keep it coherent and directed: (i) contextual cues signal the presence of an outlandish genre (or makebelieve game) and generally determine when the departure occurs and in what direction, and (ii) the imagining in the departure is still inferentially governed by genre truth attitudes, which effectively give the rules of the game. To unify these points, we can think of constructive imagination as exploratory constraint satisfaction: much imagination is representational exploration of what reality would be like if minimally altered, in which case background beliefs and percepts constrain the imagining; in other cases, imagination is representational exploration of what the world would be like if more drastically altered, in which case a set of genre truth attitudes replaces a subset of one's beliefs in supplying the constraints. Presumably, part of what makes imagination voluntary is that we can choose what to have as constraints on any given act of imagining. But although the direction of constructive imagination can be voluntarily altered, the principles that govern it usually operate swiftly, automatically, and in absence of any conscious choice on the part of the agent. That, to a great extent, is why imagination seems mysterious.

\title{
Conclusion: link to Part II
}

We still have much to do before understanding our dragon representations from the beginning. "X imagines a purple-eyed dragon" can make different claims: a constructive process claim, an attitude claim, or an imagery claim. So far, we've gained some insight into the constructive process. Constructive imagination uses perceptions you've stored in memory, like the shape of reptilian eyes and the color purple, to compose the dragon imagery. Furthermore, in addition to beliefs, it uses genre truth attitudes to infer further features of the dragon, given what's already been imagined. It follows that fictional imaginings, as attitudes, are not only one of the products of constructive imagination; they are also implicated in the generating process. It remains for us, then, to describe the attitude of fictional imagining more directly in Part II, as well as the effects of that state on emotion and action.

\author{
Neil Van Leeuwen \\ Georgia State University \\ University of Johannesburg
}




\section{Acknowledgements}

For exchanges that contributed helpfully to the shaping of this article, I would like to thank Tim Bayne, Tamar Gendler, Amy Kind, Sam Liao, Bence Nanay, Stephen Stich, and an anonymous referee. I would also like to thank Alan Richardson for bringing up the dancing cat example in response to a presentation I gave in Harvard's Cognitive Theory and the Arts seminar on February 18, 2010. I've been thinking about it ever since.

\section{References}

Currie, G., and I. Ravenscroft (2002) Recreative Minds: Imagination in Philosophy and Psychology, Oxford: Oxford University Press.

Fodor, J. (1975) The Language of Thought, Cambridge: Harvard University Press.

Fodor, J. (1983) The Modularity of Mind, Cambridge: MIT Press.

Goldman, A. (2006) "Imagination in Responses to Fiction," In The Architecture of the Imagination, ed. Shaun Nichols, 41-56, Oxford: Oxford University Press.

Harris, P. (2000) The Work of the Imagination, Oxford: Blackwell.

Hume, D. (1748/1993) An Enquiry Concerning Human Understanding, Indianapolis: Hackett.

Kaplan, D. (1968) “Quantifying In,” Synthese 19: 178-214.

Kind, A. (2001) "Putting the Image Back in Imagination," Philosophy and Phenomenological Research 62: 85-109.

Kind, A. (forthcoming) "The Heterogeneity of Imagination," Erkenntnis.

Kosslyn, S., Thompson, W., and Ganis, G. (2006) The Case for Mental Imagery, Oxford: Oxford University Press.

Kung, P. (2010) "Imagining as a Guide to Possibility," Philosophy and Phenomenological Research 81 (3):620-663.

Lillard, A. S and Witherington, D. C. (2004) “Mothers' Behavior Modifications During Pretense and Their Possible Signal Value for Toddlers," Developmental Psychology 40(1): 95-113.

Nichols, S., and S. Stich (2000) “A cognitive theory of pretense," Cognition 74 (2): 115-147.

Nichols, S., and S. Stich (2003) Mindreading, Oxford: Oxford University Press.

Shah, N., and Velleman, J. D. (2005) “Doxastic Deliberation,” Philosophical Review 114(4): 497-534.

Slotnick, S., Thompson, W., and Kosslyn, S. (2005) "Visual mental imagery induces retinotopically organized activation of early visual areas," Cerebral Cortex 15(10): 1570-1583.

Stich, S. (2009) "Reply to Goldman," in Stich and his Critics ed. Dominic Murphy, 208-215. Oxford: Oxford University Press.

Walton, K. (1990) Mimesis as Make-Believe, Cambridge: Harvard University Press.

Weisberg, D. S. and Goodstein, J. (2009) "What belongs in a fictional world?" Journal of Cognition and Culture, 9, 69-78.

White, A. R. (1990) The Language of Imagination, Oxford: Basil Blackwell. 